\title{
CARACTERIZAÇÃO DA CASCA CERÂMICA GERADA NO PROCESSO DE FUNDIÇÃO DE PRECISÃO*
}

\author{
Alini Luisa Diehl Camacho ${ }^{1}$ \\ Carlos Alberto Mendes Moraes ${ }^{2}$ \\ Regina Célia Espinosa Modolo ${ }^{3}$
}

\section{Resumo}

Este artigo apresenta a caracterização física, química e mineralógica do resíduo casca cerâmica (RCC) gerado em indústria de fundição de precisão. Este setor tem predominância nas regiões sul e sudeste do país com cerca de 35 empresas das quais cada uma gera mensalmente de 50 a 100 toneladas do resíduo. Desta forma, apresenta-se uma metodologia baseada na caracterização do resíduo como forma de reciclagem interna cujo foco é a sua valorização. A metodologia aplicada para o desenvolvimento do estudo envolveu uma caracterização físico-química do RCC obtido através de etapas de moagem. Os parâmetros analisados foram distribuição granulométrica, massa específica, área superficial, composição química quantitativa e mineralógica estrutural semi-quantitativa. A partir da segregação do material foi possível realizar a separação de materiais nobres presentes no resíduo. Em especial, as frações $40(4.25 \mathrm{~mm})$ e $80(1.80 \mathrm{~mm})$ concentrou $72.12 \%$ do total da massa do material. Apesar de apresentar um alo de amorfismo entre os ângulos 0 a $15^{\circ}$, o RCC tem comportamento predominantemente cristalino. Considerando a caracterização realizada e bibliografia referenciada, este material tem grande potencial como matéria-prima refratária, seja no processo de origem como em outras aplicações.

Palavras-chave: Caracterização; Resíduo casca cerâmica; Fundição de precisão; Valorização.

\section{CHARACTERIZATION OF CERAMIC SHELL GENERATED IN PROCESS INVESTMENT CASTING}

\section{Abstract}

This paper presents the physical, chemical and mineralogical ceramic shell residue (CSR) generated in precision casting industry. This sector has dominated the South and Southeast regions of the country with about 35 companies each of which generates monthly from 50 to 100 tons of waste. Thus, a methodology based on the characterization of waste as a form of internal recycling which focuses on recovery is presented. The methodology used for the development of the study involved a chemical-physical characterization of the RCC obtained by grinding steps. The parameters analyzed were particle size distribution, density, surface area, quantitative chemical composition and semi-quantitative structural mineralogical composition. Starting material segregation was possible to perform the separation of fine material present in the waste. In particular, the fraction of $40(4.25 \mathrm{~mm})$ and $80(1.80 \mathrm{~mm})$ concentrated $72.12 \%$ of the total mass of the material. Although present an alo amorphousness between the angles 0 to 15, the RCC has predominantly crystalline behavior. Considering performed and referenced bibliography characterization, this material has great potential as a refractory raw material is in the original procedure as in other applications.

Keywords: Characterization; Waste ceramic shell; Investment casting; Valuation.

1 Gestora Ambiental, Mestranda em Engenharia Civil, Núcleo de Caracterização de Materiais (Nucmat), Laboratorista LCVMat, Universidade do Vale do Rio dos Sinos (UNISINOS), Rio Grande do Sul, Brasil.

2 Membro da ABM, Eng. Metalúrgico, Prof. Dr., Programa de Pós Graduação em Eng. Civil, NUCMAT, UNISINOS, RS, Brasil.

3 Engenheira Agrônoma, Prof. Dra. Programa de Pós Graduação em Eng. Civil, NUCMAT, UNISINOS, RS, Brasil. 


\section{INTRODUÇÃO}

A Política Nacional de Resíduos Sólidos (2010) impõe regras para a gestão e gerenciamento de resíduos sólidos que estimula as empresas a adotarem práticas de redução, minimização dos custos totais do seu produto ou que agreguem valor ao mesmo tornando o seu processo produtivo economicamente mais rentável, competitivo e mais sustentável. (1)

A implementação de regulamentos mais restritivos nos últimos anos tem obrigado e conscientizado as empresas geradoras de resíduos sólidos a destinarem seus rejeitos para aterros industriais, muitas vezes distantes de sua localidade, onerando custos de armazenamento e transporte. ${ }^{(2)}$

Um dos principais desafios como forma de abordagem dos resíduos sólidos é como classificá-lo pela forma como eles são produzidos e o corpo receptor onde serão lançados. Esta forma tradicional de abordagem faz parte de uma visão fim-de-tubo para resolução do problema. Esta visão pode ser enfocada como uma evolução de forma a procurar maior eficiência para uma sociedade mais sustentável e vai desde a disposição de resíduos e tratamento (fim-de-tubo), prevenção da poluição como formas de reciclagem, melhorias na operação e modificações no processo até nas últimas tendências como modificações no produto, ecologia industrial e consumo sustentável. Desta forma aumenta-se a racionalidade e a produtividade no uso dos recursos naturais alinhando-se ganhos ambientais e econômicos. ${ }^{(3)}$

O processo industrial de fundição de precisão é utilizado para a produção de peças metálicas que se caracteriza pelo excelente acabamento superficial, precisão dimensional, obtenção de formatos simples a complexos e aplicações para diferentes tipos de ligas. Todas estas vantagens permitem oferecer peças com exigências para o mercado como: indústrias automobilísticas, aeronáutica, têxtil, alimentícia, agrícola, médica, odontológica, dentre outras. ${ }^{(2,4)}$

Neste processo, um modelo de cera é produzido formando uma árvore que é imersa em uma suspensão cerâmica que é então recoberta por " $n$ " camadas de material cerâmico refratário e posta para secagem. Esta imersão pode ser realizada várias vezes e vai depender das propriedades desejadas no produto. Os materiais cerâmicos refratários utilizados neste processo devem suportar altas temperaturas e serem totalmente inertes para evitar reações entre o metal e o molde. ${ }^{(5,6)}$

Os materiais utilizados no processo são óxidos com elevada pureza e estão incluídos neste grupo os materiais: mulita $\left(3 \mathrm{Al}_{2} \mathrm{O}_{3} .2 \mathrm{SiO}_{2}\right)$, sílica eletrofundida $\left(\mathrm{SiO}_{2}\right)$, sílica coloidal, aluminossilicatos, areia e farinha de zircônio $\left(\mathrm{ZrSiO}_{4}\right)$. O tamanho das partículas destes materiais refratários é limitado pelo detalhe superficial da peça a ser produzida e os pós finamente moídos são necessários a uma faixa específica de tamanho que vai de 100 a 325 mesh $(0.150$ a $0.045 \mathrm{~mm})$ e são predominantemente muito pequenos com partículas que se estendem até faixa de tamanho coloidal. ${ }^{(9)} \mathrm{A}$ confecção da casca cerâmica se dá em várias etapas e após sinterizada o metal líquido pode ser vazado. Ao final do processo, para retirada da peça metálica solidificada, a casca cerâmica precisa ser quebrada, transformando-se em resíduo sólido (RCC). ${ }^{(6,7)}$

Estes resíduos são armazenados temporariamente em locais provisórios e geralmente nos fundos da empresa. O reaproveitamento através da reciclagem de resíduos pode ser uma alternativa ambiental e econômica de forma a reinseri-los dentro do próprio processo ou valorizá-los de maneira a agregar valor na busca do desenvolvimento de novos produtos a partir dos resíduos. Sendo o $7^{\circ}$ maior produtor de fundidos, o Brasil possuiu 35 empresas de fundição de precisão que se concentram na região sul e 
sudeste e o volume gerado de RCC, em média, são de 50 a 100 toneladas por mês. (8)

As cascas cerâmicas de fundição de precisão são bem desenvolvidas e vários estudos são aprimorados para o processo de otimização, pois trata-se de compósitos complexos e certas alterações na composição não são possíveis. Algumas propriedades requeridas nas cascas devem ser respeitadas para que os materiais reciclados satisfaçam tais requisitos como resistência a verde, resistência da casca sinterizada, alta resistência a choque térmico para evitar trincas, estabilidade química, baixa reatividade com metais, permeabilidade para saída de gases, condutividade térmica e baixa expansão térmica. Manter a transferência térmica adequada através das paredes do molde permite o resfriamento do metal e facilita a remoção da casca, pois o molde deve suportar as tensões físicas e térmicas durante o manuseio provocado pelo metal durante o vazamento. $(9,6,10)$

A separação de componentes de zircônio dos outros componentes do resíduo foi testada por métodos de flotação, separação por gravidade, lixiviação cáustica e por peneiramento. Experiências de flotação com agente coletor de acetato de cocamina mostraram-se bem-sucedidas, porém o uso de agentes orgânicos eleva os custos da reciclagem. ${ }^{(9)}$

Através de uma pesquisa de várias fundições nos EUA e Canadá, em 1992 encontrouse empresas que realizavam o processo de reciclagem do resíduo através de sua moagem em moinho de barras com dimensionamento para as malhas de $100(0.150$ $\mathrm{mm}), 150(\sim 0.106 \mathrm{~mm}), 200(0.075 \mathrm{~mm})$ e $400(0.038 \mathrm{~mm})$. As frações de tamanhos concentrados continham $86,7 \%$ de componentes de zircônio para uma recuperação de $61,2 \%$. Através de uma lixiviação cáustica de $\mathrm{NaOH}$ por uma hora a $160^{\circ} \mathrm{C}$ a concentração deste componente foi de $61,2 \%$ para $90,8 \%$. ${ }^{(9)}$

Os benefícios econômicos da reciclagem interna oferecem vantagens que facilitam no processo de decisão em função da avaliação de custos do processo produtivo, pois aumentam a eficiência e evitam custos crescentes com disposição final. Desta forma, apresenta-se neste artigo uma caracterização física, química e mineralógica do resíduo casca cerâmica (RCC). O material foi analisado por distribuição granulométrica, massa específica, área superficial, composição química quantitativa e composição mineralógica estrutural semi-quantitativa.

\section{MATERIAIS E MÉTODOS}

O resíduo foi coletado em indústria localizada na serra gaúcha do RS e amostrado de acordo com a NBR 10007:2004. (11)

Para a caracterização física, química e mineralógica foram realizados ensaios conforme segue itens 2.1, 2.2 conforme fluxograma da figura 1.

Os moinhos utilizados foram: moinhos de facas, moinho de rolo por esmagamento, moinho de bolas e metodologia adaptada conforme apresenta a literatura. ${ }^{(12,13)}$

Em seguida, o material foi peneirado para avaliação da sua distribuição granulométrica. Para caracterização física (massa específica e área superficial), química e mineralógica, o RCC foi desagregado manualmente e moído em moinho automático de ágata por cerca de 30 minutos. 

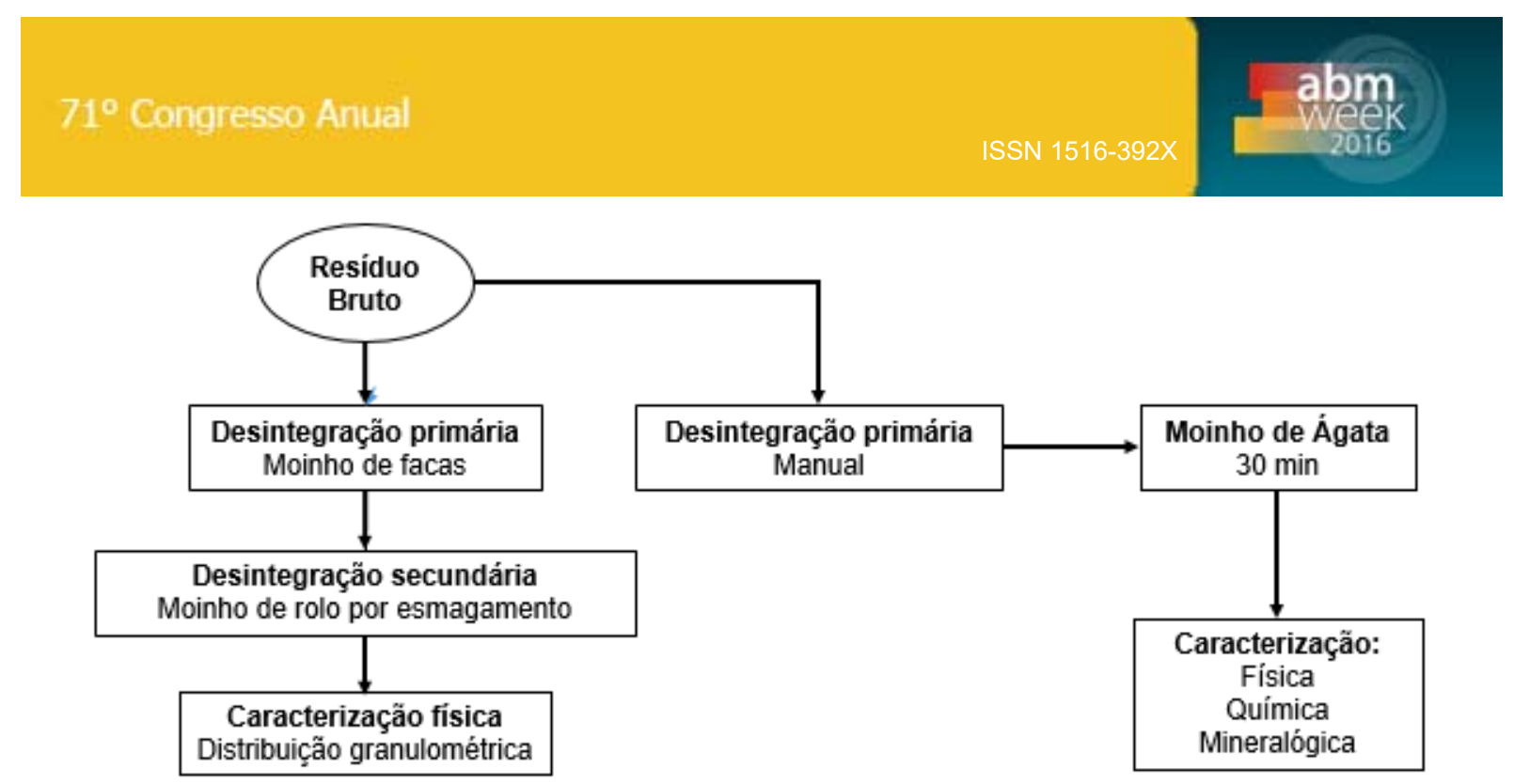

Figura 1: Metodologia utilizada para a caracterização do RCC.

\subsection{Caracterização Física}

O RCC em estudo gerado no processo de fundição de precisão é visualmente um resíduo que tem coloração clara na parte externa da casca e uma fina camada escura na sua parte interna. Apresenta dimensões que variam entre 2 e $20 \mathrm{~cm}$, variação esta que depende da peça metálica a ser produzida. Na Figura 2 são apresentadas amostras do RCC como são geradas. Os itens 2.1.1 a 2.1.4 referem-se às técnicas adotadas para a caracterização física do RCC.

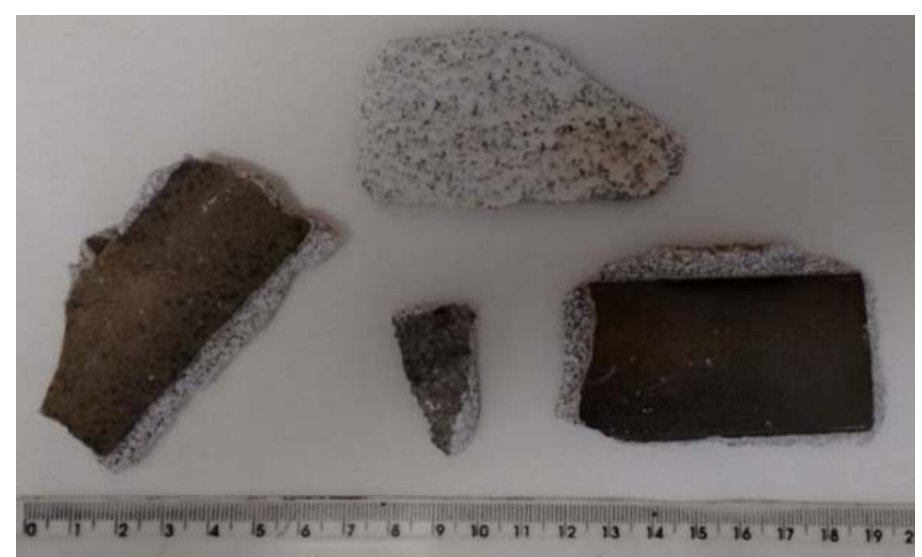

Figura 2: Resíduo casca cerâmica bruto (RCC).

\subsubsection{Distribuição Granulométrica}

Realizado de acordo com a norma CEMP (14) $n^{\circ} 081$ - Determinação da distribuição granulométrica e módulo de finura. Esta análise consiste em utilizar um conjunto de peneiras padronizadas pela ABNT (Associação Brasileira de Normas Técnicas) e calcular a massa do material retido em todas as peneiras. O resultado é expresso em porcentagem em relação à massa total de amostra. O coeficiente de distribuição é a soma das três peneiras consecutivas que mais apresentam material retido. Denominam-se finos o valor percentual retido nas duas últimas peneiras $(0.045 \mathrm{~mm}$ e $0.038 \mathrm{~mm}$ ), mais o prato. O módulo de finura corresponde ao valor resultante da série normal citadas anteriormente, dividido por 100. O módulo de finura quantifica se o material é mais grosso ou mais fino, sendo que quanto maior o módulo de finura mais grosso é o material. ${ }^{(14)}$ 


\subsubsection{Perda ao Fogo}

Através desta análise pode-se determinar a quantidade de matérias orgânicas e voláteis contidas na amostra. Este ensaio foi realizado de acordo com a norma CEMP (15) $\mathrm{n}^{\circ} 120$. A perda ao fogo consiste em colocar $1 \mathrm{~g}$ de amostra, previamente seca em estufa, a $105^{\circ} \mathrm{C}$, em forno mufla a $950^{\circ} \mathrm{C}$, durante 3 horas. Após, material é pesado até atingir massa constante. A diferença de peso inicial e final é o resultado da análise. (15)

\subsubsection{Massa Específica}

Determina a relação massa/volume em $\mathrm{cm}^{3}$ de determinada amostra e foi utilizada tanto no resíduo inicial, quanto nas frações obtidas através de sua moagem. Esta técnica é realizada por picnometria a gás hélio pelo equipamento Accupyc II 1340, marca Micromeritics.

\subsection{4 Área Superficial Específica}

Determina através da adsorção de gás nitrogênio pelo método BET (Branauer, Emmett e Teller) a relação massa/área em $\mathrm{m}^{2}$ de determinada amostra e foi utilizada tanto no resíduo inicial, quanto nas frações obtidas através de sua moagem. Esta técnica foi realizada pelo equipamento Tristar II Plus, marca Micromeritics.

\subsection{Caracterização Química e Mineralógica}

A composição química de forma quantitativa do RCC moído quanto de suas frações foi realizada por espectrometria de Fluorescência de Raios X (FRX) e o programa para quantificação utilizado foi o OMNIAN 37, equipamento PANalytical, modelo Axios.

Como técnica mineralógica foi realizada a Difração por Raios $X(D R X)$, equipamento PANalytical, modelo X'Pert PRO. O programa para interpretação dos picos cristalinos foi o X'Pert HighScore da Philips. A referência de proporção e intensidade (RIR) foi empregado para determinar o conteúdo de cada fase cristalina de forma semiquantitativa. Ambas as técnicas, FRX e DRX, são não destrutivas para todos os tipos de amostras ${ }^{(16)}$.

\section{RESULTADOS E DISCUSSÃO}

\subsection{Caracterização Física}

A distribuição granulométrica do RCC está ilustrada na Tabela 1. Percebe-se que o teor de finos é cerca de $11 \%$ e que mais de $50 \%$ em massa do total do material se concentra na fração $40(4.250 \mathrm{~mm})$. A massa específica e a área superficial do RCC são apresentadas na Tabela 2. 
Tabela 1: Distribuição Granulométrica do RCC

\begin{tabular}{|c|c|c|}
\hline Malhas (mesh) & Malhas (mm) & $\begin{array}{c}\text { Distribuição } \\
\text { granulométrica (\%) }\end{array}$ \\
\hline 40 & 4.250 & 56.90 \\
\hline 80 & 1.800 & 15.22 \\
\hline 100 & 0.150 & 1.74 \\
\hline 140 & 0.106 & 5.58 \\
\hline 200 & 0.075 & 4.19 \\
\hline 270 & 0.053 & 3.86 \\
\hline 325 & 0.045 & 1.66 \\
\hline 400 & 0.038 & 1.54 \\
\hline Fundo & Prato & 8.63 \\
\hline \multicolumn{3}{|c|}{ Módulo de Finura: 3440,39 ABNT } \\
\hline \multicolumn{3}{|c|}{ Teor de Finos: $11,83 \%$} \\
\hline \multicolumn{3}{|c|}{ Coeficiente de Distribuição: $84.31 \%$} \\
\hline
\end{tabular}

Tabela 2: Massa Específica e Área superficial do RCC

\begin{tabular}{l|c|c}
\hline Material & $\begin{array}{c}\text { Massa específica } \\
\left(\mathbf{g} / \mathbf{c m}^{\mathbf{3}}\right)\end{array}$ & $\begin{array}{c}\text { Área superficial } \\
\left(\mathbf{g} / \mathbf{m}^{\mathbf{2}}\right)\end{array}$ \\
\hline RCC & 2.9284 & 0.5931 \\
\hline
\end{tabular}

\subsection{Caracterização Química e Mineralógica}

O resultado analítico quantitativo para o ensaio de fluorescência de raios $\mathrm{X}$ que indica os elementos químicos inorgânicos presentes em óxido mais estável e a \% em matéria orgânica (L.O.I) está apresentado na Tabela 3. Verifica-se que os elementos Si e Al são majoritários na composição geral do RCC. A composição semi-quantitativa realizada das fases cristalinas por DRX no RCC está apresentada na Tabela 4 e o difratograma com os picos identificados na Figura 3.

Tabela 3. Análise química quantitativa realizada no RCC utilizando a técnica de Fluorescência de raios $\mathrm{X}$

\begin{tabular}{lccclc}
\hline Material & $\mathrm{SiO}_{2}$ & $\mathrm{Al}_{2} \mathrm{O}_{3}$ & $\mathrm{Zr}$ & Elementos traços >2\% & L.O.I \\
\hline $\mathrm{RCC}$ & 49.22 & 40.92 & \multirow{2}{*}{4.82} & $\begin{array}{l}\mathrm{Fe}, \mathrm{Ti}, \mathrm{Na}, \mathrm{Mg}, \mathrm{P}, \mathrm{S}, \mathrm{K}, \mathrm{Ca}, \mathrm{Cr}, \\
\mathrm{Mn}, \mathrm{Zn}, \mathrm{Sr}, \mathrm{Y}, \mathrm{Nb}, \mathrm{Ce}, \mathrm{Nd}, \mathrm{Hf}\end{array}$ & 0.15 \\
\hline
\end{tabular}

Tabela 4. Análise mineralógica realizada no RCC por Difração de Raios X

\begin{tabular}{lccc} 
Material & $\begin{array}{l}\text { Mulita } \\
\left(3 . \mathrm{Al}_{2} \mathrm{O}_{3} . \mathrm{SiO}_{2}\right)\end{array}$ & $\begin{array}{l}\text { Componentes de } \\
\text { Zircônio }\left(\mathrm{ZrSiO}_{4}\right)\end{array}$ & $\begin{array}{l}\text { Quartzo } \\
\left(\mathrm{SiO}_{2}\right)\end{array}$ \\
\hline $\mathrm{RCC}$ & 80.8 & 14.1 & 5.1 \\
\hline
\end{tabular}

Na figura 3, o difratograma identificou como resultado semi-quantitativo $14.10 \%$ de areia ou farinha de $\left(\mathrm{ZrSiO}_{4}\right), 80.80 \%$ de mulita $\left(3 \mathrm{Al}_{2} \mathrm{O}_{3} .2 \mathrm{SiO}_{2}\right)$ e $5.10 \%$ de sílica $\left(\mathrm{SiO}_{2}\right)$ na estrutura quartzo. Um alo de amorfismo pode ser visualizado com deslocamento da linha de base entre os ângulos 0 e $15^{\circ}$ e o restante do material analisado apresenta estrutura cristalina. 


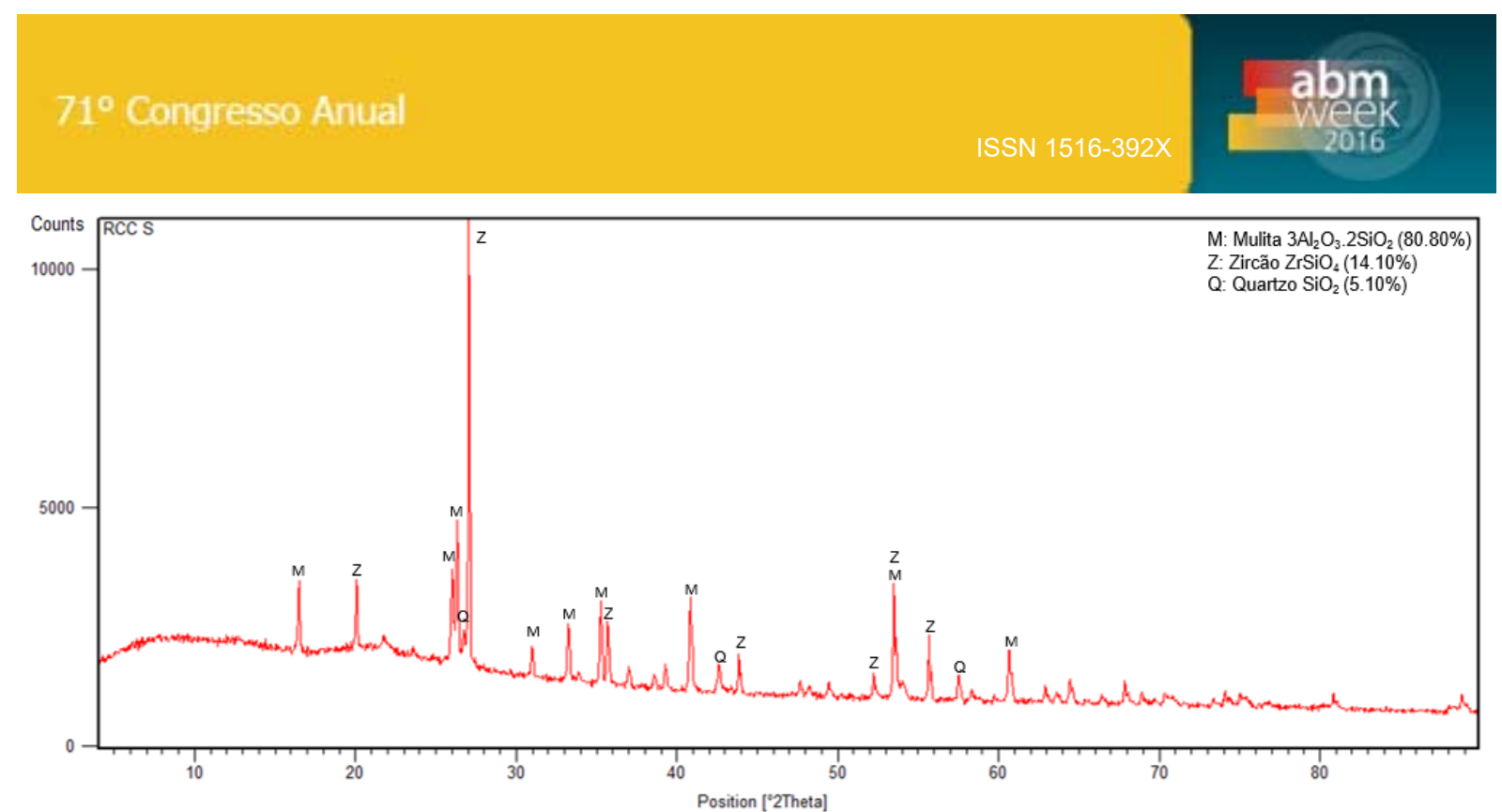

Figura 3: Difratogramas do RCC.

Pós finamente moídos de sílica eletrofundida e componentes de zircônio ou misturas dos dois são os refratários mais comuns no processo de fundição de precisão. A sílica eletrofundida é o componente mais predominante da camada refratária primária devido a sua excelente característica de trabalho porque possui resistência ao choque térmico e mantem estabilidade dimensional dos moldes.

A farinha de zircônio é estável a altas temperaturas e não sofre transformações de fases em sua estrutura cristalina. Devido ao seu elevado custo, esta matéria-prima é misturada com a sílica e ainda com areias de zircônio numa granulometria maior.

Camadas mais externas são formadas por refratários aluminossilicatos como a mulita e silicato de alumínio em tamanhos maiores de partícula e a quantidade utilizada é maior em relação as outras matérias-primas, isto pode ser verificado na peneira 40 (4.25 mm) onde concentrou $52.90 \%$ em massa do total do material moído e na peneira $80(1.80 \mathrm{~mm})$ com $15.22 \%$, o que totaliza $72.12 \%$ em massa apenas nestas duas frações. ${ }^{(9)}$

Sugere-se investigar através do processo de moagem uma melhor separação dos componentes e remover o teor de componentes de zircônio presente na composição do RCC através de uma análise química e mineralógica por fração. Um sistema de beneficiamento do RCC através de uma caracterização mais detalhista por fração requer maior atenção para avaliar em qual fração se concentram teores maiores de componentes de zircônio. Paralelamente uma avaliação através da caracterização física, química e mineralógica das matérias-primas originais comparando-as com as frações obtidas no processo de beneficiamento deve ser investigada.

\section{CONCLUSÃO}

O alo de amorfismo visualizado na técnica de DRX deve ter uma atenção especial, pois através do beneficiamento sugerido, esta fração pode ser separada do total e utilizada no desenvolvimento de um novo produto ou reinserida no processo, pois pode corresponder a fração de sílica eletrofundida (amorfa) que não cristalizou totalmente. A fração de sílica na estrutura cristalina quartzo não pode ser reinserida novamente no processo, pois compromete as características da casca cerâmica numa nova formulação.

Portanto, novas técnicas de separação física devem ser estudadas evitando ao máximo a utilização de reagentes químicos orgânicos. Uma avaliação do processo de reciclagem analisando a energia utilizada e o gasto com maquinário também deve ser 
analisado. Mesmo que de uma maneira mais ampla, a utilização das frações separadas dentro do próprio processo deve ser testada, pois grande parte do material não sofre transformações de fase e as frações 40 e $80(4.25$ e $1.80 \mathrm{~mm})$ que apresentaram mais de $70 \%$ do total do material segregado pode ser utilizado como material mais grosseiro nas últimas camadas do processo de formação da casca cerâmica.

Sendo assim, após ajustado a reciclabilidade do RCC no processo internamente é importante buscar desenvolver uma aplicação para o material que não possa ser reaproveitado evitando ao máximo seu descarte no meio ambiente e avaliar quantos ciclos é possível realizar com os materiais presentes.

Todavia, mudar o controle da poluição para sua prevenção evita com que materiais nobres que apresentam potencial para utilização, seja no mesmo processo ou ainda em novos produtos, sejam descartados sem qualquer tipo de reciclagem. Isso evita custos de transporte e disposição final, além do ganho ambiental incalculável através da utilização de recursos naturais não renováveis.

\section{Agradecimentos}

Os autores agradecem a Unisinos pela oportunidade, ao LCVMat (Laboratório de Caracterização e Valorização de Materiais), à empresa Sulmaq pela doação do resíduo e a Universidade de Aveiro pelos ensaios de FRX (Departamento de Geociências) e DRX (Departamento de Engenharia de Materiais e Cerâmica $\mathrm{DEMaC})$.

\section{REFERÊNCIAS}

$1 \quad$ BRASIL. Lei $n^{\circ}$ 12.305, de 2 de agosto de 2010. Institui a Política Nacional de Resíduos Sólidos; altera a Lei no 9.605, de 12 de fevereiro de 1998; e dá outras providências. Disponível em: <http://www.planalto.gov.br/ccivil_03/_ato20072010/2010/lei/l12305.htm>. Acesso em: jan. 2016.

2 MACHADO, C. F. Reutilização da casca cerâmica do processo de fundição por cera perdida, como adição em matrizes cimentícias. 2013. 109 p. Dissertação (Mestrado em Engenharia de Materiais) - Centro Federal de Educação Tecnológica - CEFET, Belo Horizonte, 2013.

3 KIPERSTOK, A.; COELHO, A.; TORRES, E. A.; MEIRA, C. C.; BRADLEY, S. P.; ROSEN, M. Prevenção da Poluição. Brasília. SENAI/DN, 2002.

4 CARVALHO, A. C. Reaproveitamento de resíduo cerâmico refratário como fonte alternativa mineral na produção de filtros para metais fundidos. Joinville, 2013. 75 p. Dissertação (Mestrado em Engenharia de Processos) - Universidade da Região de Joinville, Joinville, SC. 2013.

5 MACHADO, I. Avaliação microestrutural de cascas cerâmicas utilizadas na produção de moldes para o processo de fundição por cera perdida. 2005. 119 p. Dissertação (Mestrado em Engenharia Metalúrgica e de Minas) - Universidade Federal de Minas Gerais, Belo Horizonte, 2005.

6 PRASAD, R. Progress in Investment Castings. Disponível em: $<$ http://cdn.intechopen.com/pdfs/39309/In Tech-Progress_in_investment_castings .pdf>. Acesso em jan. 2016.

7 MACHADO, I. M. L. Tecnologia básica do processo de fundição por cera perdida. SENAI, Belo Horizonte, 2001.

8 LACERDA, S. S.; JOSÉ, A. A.; BORDIN, S. E. Valorização da casca cerâmica residual do processo de microfusão por incorporação em formulação de refratários. ABIFA. V. 137 p. 88-95, 2011. 
9 PETERS, T. M.; TWAROG, D. L. The feasibility of reclaiming investment shell material from investment casting. Hazardous Waste Research and Information Center One East Hazelwood Drive. Champaign, Illinois 61820, HWRIC Project RRT-10, 1992.

10 LEONARDO, I. M. Avaliação microestrutural e propriedades de cascas cerâmicas contendo diferentes tamanhos e concentrações de nanopartículas de sílica coloidal. 2013. 247 p. Tese (Doutorado em Engenharia Metalúrgica, Materiais e de Minas). Universidade Federal de Minas Gerais, Belo Horizonte, MG. 2013.

11 ASSOCIAÇÃO BRASILEIRA DE NORMAS TÉCNICAS (ABNT). NBR 10007: Amostragem de Resíduos Sólidos. Rio de Janeiro, 2004.

12 BOBROWSKI, A.; DAŃKO, R.; HOLTZER, M.; ZYCH, J. Reclamation of material from used ceramic moulds applied in the investment casting technology. Archive soffoundry engineering V.10 p.199-204. 2010.

13 DRAJEWICZ, M.; PYTEL, M. Recycling processo of casting molds applying to precision castings. Journal of Achievements in Materials and Manufacturing Engineering. V. 55 (2) p. 661-667, 2012.

14 ASSOCIAÇÃO BRASILEIRA DE FUNDIÇÃO. CEMP (Comissão de Estudos de Matérias Primas) $n^{\circ}$ 081: Materiais para Fundição - Determinação da Distribuição Granulométrica. São Paulo: ABIFA, 2003.

15 ASSOCIAÇÃO BRASILEIRA DE FUNDIÇÃO. CEMP (Comissão de Estudos de Matérias Primas) $n^{\circ}$ 120: Materiais para Fundição - Determinação da Perda ao Fogo. São Paulo: ABIFA, 2003.

16 SALVADOR, Vera Lúcia Ribeiro. Introdução a Técnica de Espectrometria de Fluorescência de Raios-X. Apostila. Shimadzu. 2007. 